\title{
ChemComm
}

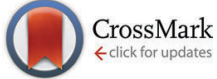

Cite this: Chem. Commun., 2016, 52, 4906

Received 6th December 2015, Accepted 7th March 2016

DOI: $10.1039 / c 5 c c 10040 b$

www.rsc.org/chemcomm

\section{Imidazolium-tagged glycan probes for non-covalent labeling of live cells $\dagger$}

\author{
David Benito-Alifonso, ${ }^{a}$ Shirley Tremell, ${ }^{a}$ Joanna C. Sadler, ${ }^{a}$ Monica Berry ${ }^{* b}$ and \\ M. Carmen Galan*a
}

Selective, bioorthogonal and fast labeling of glycoconjugates in living cells is a major challenge for synthetic and cellular biology. Here we report the use imidazolium tagged-mannosamine derivative (ITag-Man) for the non-covalent, rapid and site-specific labeling of sialic acid containing glycoproteins using commercial $\mathrm{N}$-nitrilotriacetate fluorescent reagents in a range of cell lines.

Cell surface carbohydrates mediate cell-cell communication, bacterial or viral adhesion, neural development and cell proliferation, viral infection, masking of immunological epitopes, fertilization, neural development and cell proliferation among others. ${ }^{1}$ Surface carbohydrates can differ considerably in disease and health, and thus unique glycan markers can be exploited for early disease diagnosis and the development of vaccines and therapeutics. ${ }^{2}$ Metabolic oligosaccharide engineering (MOE) is a strategy used to highjack physiological pathways by introducing unnatural monosaccharides bearing small chemical reporters to monitor glycosylation changes. ${ }^{3}$ The labelled glycans can be transformed by the cell biosynthetic machinery into activated nucleotide sugars that are transported into the Golgi and then transferred to glycoconjugates destined for secretion, delivery to cellular compartments or presentation on the cell surface. A number of metabolic glycan reporters based on the structures of $\mathrm{N}$-acetyl-mannosamine (ManNAc), $\mathrm{N}$-acetyl-glucosamine (GlcNAc), $\mathrm{N}$-acetyl-galactosamine (GalNAc) or fucose (Fuc) have been successfully used to disrupt glycan biosynthesis, chemically modify cell surfaces, probe intracellular metabolic flux inside cells, and to identify specific glycoprotein subtypes from the proteome.,

$\mathrm{N}$-Azidoacetylmannosamine (ManNAz) is one of the most common probes used to visualize sialic acid-containing carbohydrates. ManNAz utilizes an azide functional group as the chemical reporter that can be selectively derivatized, upon being metabolized,

${ }^{a}$ School of Chemistry, University of Bristol, Cantock's Close, BS8 1TS, UK. E-mail:M.C.Galan@bristol.ac.uk

${ }^{b}$ School of Physics, University of Bristol, NSQI, Tyndall Ave, Bristol BS8 1F, UK. E-mail: mon.berry@bristol.ac.uk

$\dagger$ Electronic supplementary information (ESI) available: Experimental procedures, characterization data and live cell analysis. See DOI: 10.1039/c5cc10040b using the Staudinger ligation, ${ }^{5}$ the $\mathrm{Cu}(\mathrm{I})$ catalyzed $^{6}$ or the strainpromoted $^{7}$ azide-alkyne $[3+2]$ cycloaddition. More recently, other bioorthogonal metabolic chemical reporters that also rely on the covalent modification of the functional group at C-2 of the mannosamine moiety have been developed. ${ }^{8}$ Some of these strategies include the use of alkenes that are selectively labeled by Diels Alder reaction with inverse electron demand with a suitable fluorophore, ${ }^{8,9}$ the use of isonitriles ${ }^{10}$ and cyclopropenes ${ }^{11}$ that can react with tetrazine derivatives in a click type reaction, as well as $N$-propargyloxycarbamates that are tagged by azide-bearing molecules. ${ }^{12}$ Another elegant approach uses photoactivatable diaziridine crosslinkers to covalently trap interactions among glycoproteins. ${ }^{13}$ Despite recent advances and provided that different glycan labelling probes have been shown to follow different metabolic pathways, ${ }^{12}$ new labeling strategies that are fast, mild, bioorthogonal are still needed for the discovery and full identification of new glycan biomarkers in living cells. Furthermore, the labelling should be non-toxic to cells even at long exposure times, and should minimise undesired phenotypical changes that would compromise the interpretation of the results. Herein we report a new ionic probe (ITag-mannosamine) that is metabolically incorporated into cell-surface sialic acids and that is selectively and efficiently detected by non-covalent labeling with commercial fluorescent $\mathrm{Ni}^{2+}: N$-nitrilotriacetate (NTA-Atto). Moreover, using affinity chromatography we were able to isolate ITag-bearing glycoproteins directly from cell lysates.

Non-covalent interactions to form stable complexes between a marker and a biomolecule of interest are often used in cell biology, ${ }^{14}$ because the methods are less harsh than covalent strategies and labeling occurs at a faster rate and at physiological pH. Ionic liquids (ILs) have recently become very attractive tunable ionic supports for the immobilization of reagents. ${ }^{15}$ Our group recently reported the use of imidazolium-based IL tags (ITags) as purification labels and mass spectroscopy (MS) reporters in chemical and enzymatic oligosaccharide elongation processes. ${ }^{16}$ Encouraged by our results, we anticipated that the small cationic imidazolium moiety present in an ITag would be ideally suited for MOE (Fig. 1). 

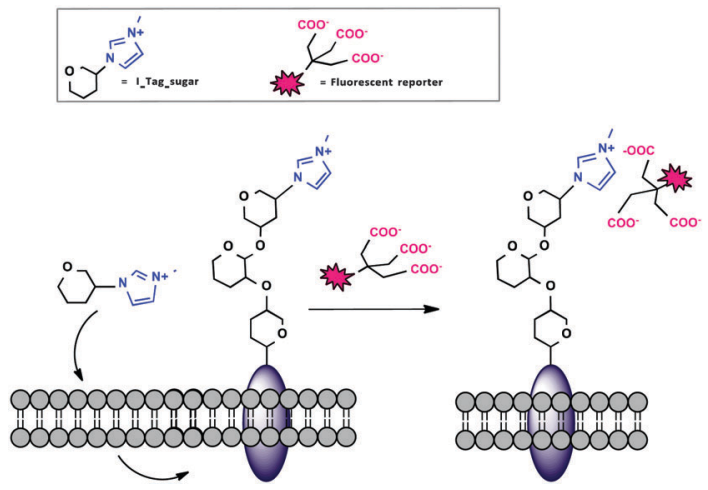

Fig. 1 General strategy for the use of ITag-sugars as non-covalent probes in MOE.

To that end, peracetylated ITag-mannosamine ( $\left.\mathrm{Ac}_{4} \mathrm{ManN}-\mathrm{ITag}, 2\right)$ was prepared from mannosamine hydrochloride, in two steps and $45 \%$ overall yield, by reaction with 3-methyl-1-imidazol-3ium-propionic acid ${ }^{17}$ using $\mathrm{EDC}$ and $\mathrm{Et}_{3} \mathrm{~N}$ in dimethylformamide (DMF), followed by acetylation with $\mathrm{Ac}_{2} \mathrm{O}$ and pyridine (Scheme 1). Deacetylation of $\mathbf{2}$ followed by treatment with commercial D-sialic acid aldolase ${ }^{18}$ in the presence of pyruvate, yielded the corresponding neuraminic acid derivative 3 (see ESI, $\uparrow$ for details), demonstrating that the ITag is tolerated by an aldolase.

$\mathrm{Ni}^{2+}$ :NTA-Atto complexes are extensively used as site-specific fluorescent labels for proteins containing oligohistidine-Tags. ${ }^{19}$ Moreover, imidazolium based ILs can form stable adducts with cation chelating/polyanion bearing molecules. ${ }^{20}$ To further explore the potential utility of the reagent in our system, NMR titrations using model IL 3-methyl-1-imidazol-3-ium-propionate with NTA analogue $N$-acetyl- $N \alpha, N \alpha$-bis(carboxymethyl)---lysine in the absence of $\mathrm{Ni}^{2+}$ showed that the IL interacts with the model NTA label in PBS buffer (pH 7.4) with an approximate binding constant of $22 \pm 9 \mathrm{mM}^{-1}$ (see ESI, $\dagger$ for details). ${ }^{21}$

A number of cell lines, including Jurkat T-lymphocytes, breast cancer cell line MDA-MB-231 (MDA), colon cancer cell line HT29-MTX-E12 (E12), cervical cancer cells HeLa and SV40immortalized human corneal epithelium (AS) cells were incubated for 3 days ${ }^{5}$ in the presence of a range of concentrations of $2(0.2-200 \mu \mathrm{M})$. Surface expression of Neu-5-N-ITag 4 was then assessed by exposure with fluorescent NTA-Atto $550\left(5 \times 10^{-8} \mathrm{M}\right)$ for $1 \mathrm{~h}$ at $37^{\circ} \mathrm{C}$. Confocal fluorescence microscopy clearly showed labeling of the cell membrane for the ITag-labeled cell lines in comparison to controls ${ }^{22}$ (Fig. 2). Fluorescence quantification revealed that expression of ITag on the cell surface varied with cell line, which is to be expected since different cell lines will have

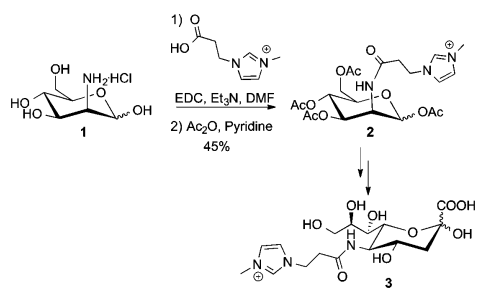

Scheme 1 Synthesis of $\mathrm{Ac}_{4}$ ManN-ITag 2.

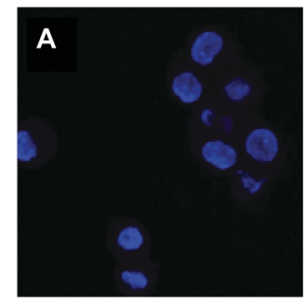

B

Fig. 2 Confocal images of E12 cells stained with nucleus staining NucBlue ${ }^{\circledR}$ and NTA-ATTO 550 (red). (A) untreated cells and (B) cells incubated with 2 at $2 \mu \mathrm{M}$ for $72 \mathrm{~h}$. For a clearer image, please refer to the electronic version of this manuscript.

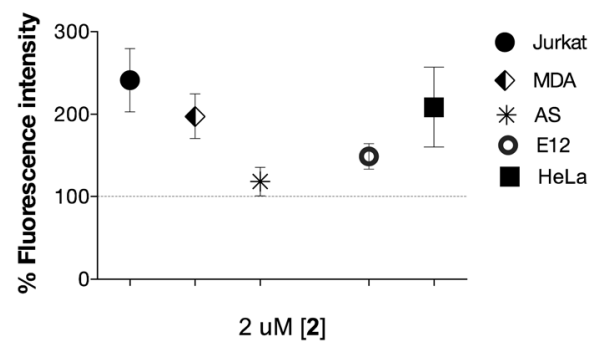

Fig. $3 \mathrm{Ni}^{2+}$ :NTA-ATTO labeling of the cell surface after incubation with $2(2 \mu \mathrm{M}$ shown) in complete cell growth. medium for $72 \mathrm{~h}$. Fluorescence is expressed as \% of control (100\%).

a differential expression of sialic acid (Fig. 3). No effect on cell numbers and metabolic activity was detected after these exposures (see ESI, $\uparrow$ for further details). In addition, HeLa, MDA and E12 cells that had been incubated with $2(2 \mu \mathrm{M})$, were treated with neuraminidase from Arthrobacter ureafaciens to remove cell surface sialic acids prior to NTA-Atto exposure. Encouragingly, cells that had been exposed to the sialidase, showed a decrease in fluorescence when compared to controls ( 2 treated cells). These results suggest that the sialidase is able to hydrolise ITag-bearing sialic acids and that NTA-Atto binds to ITag-bearing sialic acids on the cell surface.

To test whether the overall electronic charge of the cell surface was altered by the expression of imidazolium-bearing glycans, we measured the electrokinetic potential (zeta potential) ${ }^{23}$ of AS, HeLa, Jurkat and MDA cells after treatment with 2 at 0-20 $\mu \mathrm{M}$ concentrations. For AS and MDA cells, no significant changes in zeta potential could be detected, while for Jurkat and HeLa the largest negative values were measured at low concentrations of $\mathbf{2}$ with charges being restored to control values with exposure to increased concentrations of 2. These small variations could be attributed to changes in glycan expression prompted by the ITag-moieties (See Fig. S6 in ESI $\dagger$ ).

To determine the effect of ITag-probe 2 on cell surface neuraminic acid expression, AS, HeLa, Jurkat, E12, and MDA cells treated with equal concentrations of 2 were incubated with sialic acid specific biotinylated lectins: Sambucus nigra agglutinin (SNA), which binds to terminal $\alpha$-2,6-linked sialic acids preferentially, and Maackia Amurensis Lectin II (MAA), which prefers to bind sialic acid in an $\alpha$-2,3-linkage. Lectin binding was then quantified using Neutravidin DyLight $649\left(2 \mu \mathrm{g} \mathrm{mL}^{-1}\right)$ and results 


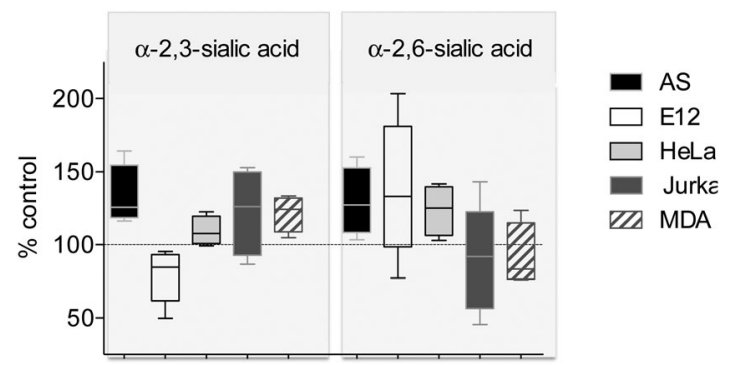

Fig. 4 Effect of treatment of $2(20 \mu \mathrm{M})$ on cell surface sialic acids for the different cell lines. Values are given as \% of untreated controls (100\%).

compared to untreated controls where these moieties are natively expressed. ${ }^{24}$ In addition to differential expression of ITag on the cell surface, the linkage of sialic acids in response to 2 depended on the cell line. Ratios of $\alpha-2,6$-linked and $\alpha-2,3-$ linked sialic acid expression varied between the different cell lines investigated and also depended on the dose of 2 to which they have been exposed (Fig. 4 and Fig. S8 in ESI $\dagger$ ). A consistent and similar increase in $\alpha-2,3$-sialic acid expression (over $\alpha-2,6$ linked) upon treatment with 2 was observed in all cell lines with the exception of mucin-secreting E12 cells, in which the $\alpha-2,6-$ linkage increased and the $\alpha-2,3$-decreased. Moreover, AS and HeLa cells presented increased $\alpha-2,6$-sialic acid levels with respect to untreated controls. ${ }^{25}$

Discrete glycocalyx alterations, such as relative changes in the composition of sialic acids, have been linked to changes in cell adhesion. ${ }^{26}$ Calcein AM was used to quantify the number of live cells in MDA, Jurkat, E12 and HeLa cells, adhering to fibronectin-coated plates. Alterations in cell surface sialic acid expression observed on incubation with 2, were insufficient to affect the number of adherent cells relative to untreated controls. Interestingly, further evaluation of the ITag-treated cells showed that after exposure to increased concentrations of $2(200 \mu \mathrm{M})$, adherent cells expressed significantly less surface ITag than cells remaining in solution. (Fig. S9-S11 in ESI $\dagger$ ) Effects on cell-cell aggregation were also quantified by the adherence of MDA, Jurkat, HeLa and E12 cells, that had been pretreated with 2 at $20 \mu \mathrm{M}$, to monolayers of treated or untreated MDA, HeLa and E12 cells, or to naked wells, in different combinations. No significant differences were observed for cell aggregation of any of the ITagtreated cells to treated or untreated cell monolayers. However, the adherence of treated cells to the naked culture plate was modified in a cell dependent manner (See Fig. S12 in ESI, $\dagger$ for further details). These alterations are concordant with modest variations in sialic acid populations at the cell surface, highlighting the importance of these glyco-epitopes in cell and tissue biology.

Encouraged by the simplicity of our protocol, we evaluated the feasibility of using affinity chromatography to isolate the glycoproteins with the metabolically incorporated ITags directly from the cell lysates. To that end, the lysate of ITag $2(20 \mu \mathrm{M})$ treated MDA cells were subjected to purification over a HitrapTM Q HP affinity column (which provides a chelate affinity medium) and proteins were eluted using an imidazolium gradient. Western blots of purified lysates (lanes 3-5) displayed discrete bands of

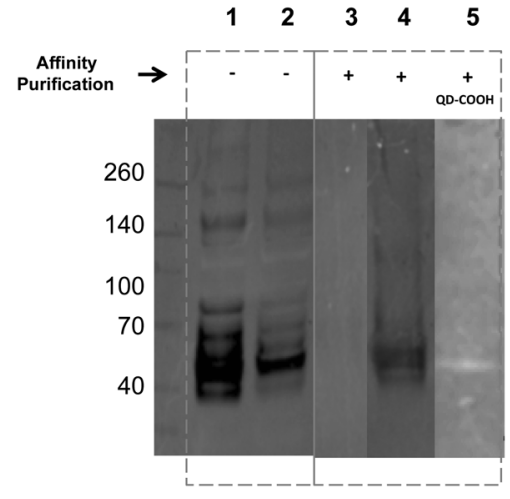

Fig. 5 Western blot of MDA cells treated with $2(20 \mu \mathrm{M})$ (lanes 2 and 4$)$ and untreated controls (lanes 1 and 3 ) before $(-)$ and after $(+)$ affinity purification and stained with sialic acid binding lectins. Lane 5 shows lysates of 2 treated cells after purification and stained with QD-COOH.

similar molecular weights (around 50 kDa, Fig. 5 and Fig. S13 in $\mathrm{ESI} \dagger$ ) and their specificity was tested by reaction with sialic acid binding lectins. Excitingly, ITag-treated lysates showed an enrichment of sialic acid containing glycoproteins as revealed by lectin staining (lane $4 v$ s. control in lane 3, Fig. 5) ${ }^{27}$ In addition, ITagtreated lysates exposed to mercaptoacetic acid coated fluorescent quantum dots (QD-COOH $)^{28}$ also tested positive on the blots (lane 5), further suggesting that the band corresponds to a glycoprotein bearing an ITag-labeled sialic acid.

In conclusion, we have developed a new class of imidazoliumbased glycan probes (ITag-Man) for non-covalent labeling of glycoconjugates in live cells with commercial fluorescent NTAAtto 550. The labeling is mild, fast, bioorthogonal and complimentary to current labeling methods. We demonstrated that the ITags are well tolerated by a number of cell lines and do not have a significant effect on cell adhesion or the overall electronic cell surface charges, however the ionic labels do have an impact on the type of sialic acid that is expressed on the cell surface $(\alpha-2,3-v s . \alpha-2,6)$. In addition, a chelating affinity column was successfully used to enrich the sample with glycoproteins specifically labeled with the new ITag-sialic acid moieties. The methodology reported here, provides a unique and practical way to label specific glycoproteins present in a variety of cells. Given the bioorthogonality and mild nature of the tags, combined with the simplicity of the protocol, we believe that the use of ITags for labeling biomolecules will not be restricted to metabolic oligosaccharide engineering, but should be broadly applicable to other biological systems.

We gratefully acknowledge financial support from EPSRC grant number EP/J002542/1 and ERC-COG (ID 648239).

\section{Notes and references}

1 (a) A. Varki and J. B. Lowe, Essentials of glycobiology, Cold Spring Harbor, NY, 2009; (b) Y. van Kooyk and G. A. Rabinovich, Nat. Immunol., 2008, 9, 593; (c) R. D. Cummings, Mol. BioSyst., 2009, 5, 1087.

2 (a) M. C. Galan, D. Benito-Alifonso and G. M. Watt, Org. Biomol. Chem., 2011, 9, 3598-3610; (b) M. C. Galan, P. Dumy and O. Renaudet, Chem. Soc. Rev., 2013, 42, 4599.

3 S. T. Laughlin and C. R. Bertozzi, Proc. Natl. Acad. Sci. U. S. A., 2009, 106, 12. 
4 B. Y. Z. Li, F. Mock and P. Wu, Methods in Enzymology, Imaging and Spectroscopic Analysis of Living Cells, 2012, vol. 505, p. 401.

5 E. Saxon and C. R. Bertozzi, Science, 2000, 287, 2007-2010.

6 S. R. Hanson, T. L. Hsu, E. Weerapana, K. Kishikawa, G. M. Simon, B. F. Cravatt and C. H. Wong, J. Am. Chem. Soc., 2007, 129, 7266.

7 (a) I. A. Khalil, K. Kogure, H. Akita and H. Harashima, Pharmacol. Rev., 2006, 58, 32; (b) X. H. Ning, J. Guo, M. A. Wolfert and G. J. Boons, Angew. Chem., Int. Ed., 2008, 47, 2253; (c) F. Friscourt, P. A. Ledin, N. E. Mbua, H. R. Flanagan-Steet, M. A. Wolfert, R. Steet and G. J. Boons, J. Am. Chem. Soc., 2012, 134, 5381; (d) H. Moller, V. Bohrsch, J. Bentrop, J. Bender, S. Hinderlich and C. P. R. Hackenberger, Angew. Chem., Int. Ed., 2012, 51, 5986.

8 (a) P. V. Chang, X. Chen, C. Smyrniotis, A. Xenakis, T. S. Hu, C. R. Bertozzi and P. Wu, Angew. Chem., Int. Ed., 2009, 48, 4030; (b) A. Niederwieser, A. K. Spate, L. D. Nguyen, C. Jungst, W. Reutter and V. Wittmann, Angew. Chem., Int. Ed., 2013, 52, 4265; (c) T. L. Hsu, S. R. Hanson, K. Kishikawa, S. K. Wang, M. Sawa and C. H. Wong, Proc. Natl. Acad. Sci. U. S. A., 2007, 104, 2614; (d) B. W. Zaro, Y. Y. Yang, H. C. Hang and M. R. Pratt, Proc. Natl. Acad. Sci. U. S. A., 2011, 108, 8146; (e) D. H. Dube, J. A. Prescher, C. N. Quang and C. R. Bertozzi, Proc. Natl. Acad. Sci. U. S. A., 2006, 103, 4819.

9 (a) A. K. Spate, V. F. Schart, S. Schollkopf, A. Niederwieser and V. Wittmann, Chem. - Eur. J., 2014, 20, 16502; (b) A. K. Spate, H. Basskamp, A. Niederwieser, V. F. Schart, A. Marx and V. Wittmann, Bioconjugate Chem., 2014, 25, 147; (c) H. Busskamp, E. Batroff, A. Niederwieser, O. S. Abdel-Rahman, R. F. Winter, V. Wittmann and A. Marx, Chem. Commun., 2014, 50, 10827.

10 (a) S. Stairs, A. A. Neves, H. Stöckmann, Y. A. Wainman, H. IrelandZecchini, K. M. Brindle and F. J. Leeper, ChemBioChem, 2013, 14, 1063; (b) Y. A. Wainman, A. A. Neves, S. Stairs, H. Stockmann, H. Ireland-Zecchini, K. M. Brindle and F. J. Leeper, Org. Biomol. Chem., 2013, 11, 7297.

11 D. M. Patterson, L. A. Nazarova, B. Xie, D. N. Kamber and J. A. Prescher, J. Am. Chem. Soc., 2012, 134, 18638.

12 (a) M. Boyce, I. S. Carrico, A. S. Ganguli, S. H. Yu, M. J. Hangauer, S. C. Hubbard, J. J. Kohler and C. R. Bertozzi, Proc. Natl. Acad. Sci. U. S. A., 2011, 108, 3141; (b) L. A. Bateman, B. W. Zaro, K. N. Chuh and M. R. Pratt, Chem. Commun., 2013, 49, 4328.

13 Y. Tanaka and J. J. Kohler, J. Am. Chem. Soc., 2008, 130, 3278.

14 G. Patonay, J. Salon, J. Sowell and L. Strekowski, Molecules, 2004, 9, 40.

15 (a) J. P. Hallett and T. Welton, Chem. Rev., 2011, 111, 3508; (b) M. C. Galan, R. A. Jones and A. T. Tran, Carbohydr. Res., 2013, 375, 35.

16 (a) I. Sittel, A. T. Tran, D. Benito-Alifonso and M. C. Galan, Chem. Commun., 2013, 49, 4217; (b) A. T. Tran, R. Burden, D. T. Racys and M. C. Galan, Chem. Commun., 2011, 47, 4526; (c) M. C. Galan, A. T. Tran and C. Bernard, Chem. Commun., 2010, 46, 8968; (d) M. C. Galan, A. T. Tran, K. Bromfield, S. Rabbani and B. Ernst,
Org. Biomol. Chem., 2012, 10, 7091; (e) I. Sittel and M. C. Galan, Bioorg. Med. Chem. Lett., 2015, 25, 4329.

17 M. C. Galan, K. Jouvin and D. Alvarez-Dorta, Carbohydr. Res., 2010, $345,45$.

18 C. Y. Chou, T. P. Ko, K. J. Wu, K. F. Huang, C. H. Lin, C. H. Wong and A. H. J. Wang, J. Biol. Chem., 2011, 286, 14057.

19 A. N. Kapanidis, Y. W. Ebright and R. H. Ebright, J. Am. Chem. Soc., 2001, 123, 12123.

20 S. Pandey, M. Ali, G. Kamath, S. Pandey, S. N. Baker and G. A. Baker, Anal. Bioanal. Electrochem., 2012, 403, 2361.

$21 \mathrm{Ni}^{2+}$ is paramagnetic and as such, spectra run in the presence of $\mathrm{Ni}^{2+}$ :NTA showed very broad signals, see ESI, $\dagger$ for details. Although quantification was not possible, small shifts in the spectra could also be observed as the $\mathrm{Ni}^{2+}$-NTA was titrated into the model IL. In addition, the proposed interaction in vitro might be different at a cellular level as many other components on the cell surface are present, which are likely to influence the binding (F. Bemaudat and L. Bulow, J. Chromatogr. A, 2005, 1066, 219).

22 Control experiments with cells cultured in absence of 2 showed some background fluorescence. This is expected as NTA-Atto recognises vicinal Histidine motifs. Results are therefore presented as percentage of untreated culture values. Treatment with 2 did not affect cell division or metabolism, except at concentration 1000 times larger than used here.

23 (a) W. W. Wilson, M. M. Wade, S. C. Holman and F. R. Champlin, J. Microbiol. Methods, 2001, 43, 153; (b) J. Wang, B. Cheng, J. Li, Z. Zhang, W. Hong, X. Chen and P. R. Chen, Angew. Chem., Int. Ed. Engl., 2015, 54, 5364.

24 The fluorescent reporters are non-cell permeable, which assures cell surface quantification, and not intracellular.

25 The fact that we see a correlation between the addition of [2] and changes in sialic acid expression suggests that sialic acid lectins could be binding to both non-ITagged and ITagged sialic acids. However, we must not exclude the possibility that exposure to 2 can elicit changes on the production of natural sialic acids.

26 (a) S. Sabri, M. Soler, C. Foa, A. Pierres, A. M. Benoliel and P. Bongrand, J. Cell Sci., 2000, 113, 1589; (b) S. Kelm, R. Schauer, J. C. Manuguerra, H. J. Gross and P. R. Crocker, Glycoconjugate J., 1994, 11, 576.

27 ITag-treated samples purified using an imidazole elution gradient $(0.02-0.5 \mathrm{M})$ showed an enrichment of glycoproteins at around $50 \mathrm{kDa}$ at $0.45 \mathrm{M}$ imidaloze. Non-treated samples subjected to the same purifications protocol had a different elution profile (Fig. S12 in $\mathrm{ESI}_{\dagger}^{\dagger}$ ).

28 D. Benito-Alifonso, S. Tremel, B. Hou, H. Lockyear, J. Mantell, D. J. Fermin, P. Verkade, M. Berry and M. C. Galan, Angew. Chem., Int. Ed., 2014, 53, 810. 